\title{
Increased serum levels of soluble CD163 in patients with scleroderma
}

Kazuhiro Shimizu ${ }^{1}$, Fumihide Ogawa $^{1}$, Ayumi Yoshizaki $^{1}$, Yuichiro Akiyama $^{1}$, Yutaka Kuwatsuka ${ }^{1}$, Shihoko Okazaki ${ }^{1}$, Hajime Tomita ${ }^{1}$, Motoi Takenaka $^{1}$, and Shinichi Sato ${ }^{1,2}$

${ }^{1}$ Departments of Dermatology, Nagasaki University Graduate School of Biomedical Sciences, Nagasaki, Japan; ${ }^{2}$ Department of Dermatology, Faculty of Medicine, University of Tokyo, Tokyo, Japan

Name and address for correspondence:

Shinichi Sato, MD, PhD

Department of Dermatology, Faculty of Medicine, University of Tokyo

7-3-1 Hongo, Bunkyo, 113-8655, Tokyo, Japan

Tel: +81-3-5800-6536

Fax: +81-3-3814-1503

e-mail: satos-der@h.u-tokyo.ac.jp

Key words: Systemic sclerosis, soluble CD163, Oxidative stress

A short running title: Serum levels of soluble CD163 in scleroderma 


\section{Abstract}

CD163 is a $130 \mathrm{kDa}$, type I transmembrane protein belonging to group B of the cysteine-rich scavenger receptor family. Expression of CD163 is constitutive and/or induced by some stimuli on circulating monocytes and most tissue macrophages. An approximately $130 \mathrm{kDa}$ soluble form of human CD163 is released from the cell surface by proteolysis after oxidative stress or inflammatory stimuli. Thus, elevated level of circulating soluble CD163 (sCD163) has been reported in diabetes mellitus, which is one of oxidative conditions. We have already acknowledged that scleroderma (SSc) is one of oxidative conditions. Therefore, we conducted to measure serum sCD163 in SSc patients. After receiving the informed consents, 56 SSc patients were examined, and 20 dermatomyositis (DM) patients as disease controls and 40 persons were used as healthy controls. Blood samples were collected and the concentration of serum sCD163 was measured by ELISA (Human CD163, R\&D Systems). Other parameters in blood of SSc patients were also examined. Statistical analyses were performed using Mann-Whitney's U-test and the relationship between parameters was statistically examined by Spearman's rank test. Serum sCD163 levels were elevated in SSc patients compared with normal controls $(\mathrm{p}<0.01)$, with similar levels between limited SSc and diffuse SSc patients. SSc patients with pulmonary fibrosis had increased serum levels of sCD163 than those without pulmonary fibrosis $(\mathrm{p}<0.05)$. SSc patients with elevated sCD163 levels had increased serum levels of IgG than those with normal sCD163 levels $(p<0.05)$. Serum sCD163 levels correlated positively with pulsatility index in SSc patients $(p=0.0009, r=0.534)$. These results suggest that the oxidative stress may play an important role in immunological abnormalities, renal circulation and pulmonary fibrosis of SSc. 


\section{Introduction}

Systemic sclerosis (SSc) is a multi-system disorder of connective tissue characterized by sclerotic changes in the skin and internal organs. Furthermore, many immunologic abnormalities, including the presence of autoantibodies and hyper- $\gamma$-globulinemia, have been detected in SSc patients, suggesting that SSc has an autoimmune background. In fact, SSc-specific Abs, including anti-topoisomerase I Abs, anti-centromere Abs, and anti-RNA polymerase Abs have been identified[1-3].

Although the pathogenesis of this disease remains unclear, oxidative stress has been suggested to contribute to clinical manifestations associated with SSc, such as vascular damage, fibrosis and immunological abnormalities[4-7]. We have already reported high values of serum 8-isoporstane, that is one of the markers of lipid peroxidation, in SSc patients[8]. To further assess the role of oxidative stress in the development of SSc, a new marker that directly reflects oxidative damages in vivo would be expected.

Meanwhile, CD163 is a $130 \mathrm{kDa}$, type I transmembrane protein belonging to group $\mathrm{B}$ of the cysteine-rich scavenger receptor family[9-11]. Expression of CD163 is constitutive and/or induced by some stimuli on circulating monocytes and most tissue macrophages. An approximately $130 \mathrm{kDa}$ soluble form of human CD163 is released from the cell surface by proteolysis after oxidative stress or inflammatory stimuli. Thus, elevated level of circulating soluble CD163 (sCD163) has been reported in diabetes mellitus, which is one of oxidative conditions[12]. However, there have been no studies examining the involvement of sCD163 in SSc patients to our knowledge.

Therefore, we conducted the present study to measure serum sCD163 levels in SSc patients and examine the correlation between serum sCD163 and clinical findings in order to determine the contribution of the tissue damage induced by oxidative stress to the development of SSc. 


\section{Patients and methods}

Serum samples

Serum samples were obtained from 56 Japanese patients with SSc (49.2 \pm 16.8 years old, 6 males and 50 females). All patients fulfilled the criteria proposed by LeRoy et al[13]. The disease duration of patients with SSc was $5.6 \pm 7.2$ years. Patients were classified into the following 2 subgroups: 24 patients with limited SSc (ISSc; 1 males and 23 females) and 32 patients with diffuse SSc (dSSc; 6 males and 26 females). None of the SSc patients were treated with steroids, D-penicillamine, prostanoids, calcium channel blockers or other immunosuppressive therapy, and none of them had a recent history of infection and abnormal liver function at the time of serum sampling. Antinuclear Ab was determined by indirect immunofluorescence using HEp-2 cells as the substrate and autoantibody specificities were further assessed by enzyme linked immunosorbent assay (ELISA) and immunoprecipitation. Anti-centromere Ab was positive for 21 patients, anti-topoisomerase I Ab for 23, anti-U1RNP Ab for 2, anti-U3RNP Ab for 3, anti-RNA polymerase $\mathrm{Ab}$ for 5 , anti-centromere $\mathrm{Ab}$ and anti-topoisomerase Ab for 1, autoantibody with unknown specificities for 2 and negative for 1 .

Forty Japanese healthy persons (45.2 \pm 10.1 years old, 5 males and 35 females) that were matched for age and sex with SSc patients were used as normal controls. Twenty patients with dermatomyositis (DM) (48.3 \pm 14.6 years old, 3 males and 17 females) were included as disease controls and they fulfilled the criteria for DM proposed by Bohan \& Peter[14], respectively. None of them were treated with immunosuppressive therapy at the time of first evaluation. Smokers were excluded in this study. Fresh venous blood samples were centrifuged shortly after clot formation. All samples were stored at $-70^{\circ} \mathrm{C}$ prior to use. The protocol was approved by our institutional review board and informed consent was obtained from all patients. 


\section{Clinical assessment}

Complete medical histories, physical examinations, and laboratory tests were conducted for all patients at their first visit. Out of 56 SSc patients studied for serum sCD163 levels, clinical and laboratory correlation was examined for 50 patients because of the limited available data. Organ system involvement was defined as described previously[15-17]: lung $=$ bibasilar fibrosis on chest radiography and high resolution computed tomography; esophagus = hypomotility shown by barium radiography; joint = inflammatory polyarthralgias or arthritis; heart = pericarditis, congestive heart failure, or arrhythmias requiring treatment; kidney = malignant hypertension and rapidly progressive renal failure without any other explanation; and muscle = proximal muscle weakness and elevated serum creatine kinase. Pulmonary function test, including vital capacity (VC) and diffusion capacity for carbon monoxide (DLco), was also tested. There were no patients with pulmonary hypertension without pulmonary fibrosis. Renal vascular damage was determined as a pulsatility index (PI), that was a parameter for renal vascular resistance determined by colour-flow Doppler ultrasonography of the renal interlobar arteries of both kidneys[18].

Rheumatoid factor (RF) (IgM) was measured by nephelometric method (N Latex RF kit II; Dade-Behring BN II, Marburg, Germany) and values>20 IU/ml were considered positive. RF (IgG) was measured by ELISA kits (Eitest IgGRF; Eisai, Tokyo, Japan) and normal cut-off value was defined as 2.0 Index.

Enzyme-linked immunosorbent assay (ELISA) for serum sCD163

The concentrations of serum sCD163 were measured by an ELISA kit (R\&D Systems, Mineapolis, MN). ELISA for sCD163 was performed according to the manufacturer's procedure. 1:10 diluted serum samples were tested in duplicate.

Statistical analysis

Statistical analysis was performed using Mann-Whitney's U test for comparison of sCD163 levels, Fisher's exact probability test for comparison 
of frequencies, and Bonferroni's test for multiple comparisons. Spearman's rank correlation coefficient was used to examine the relationship between two continuous variables. A p value less than 0.05 was considered statistically significant. All data were presented as means \pm standard deviation (SD). 


\section{Results}

Serum sCD163 levels in SSc

Serum sCD163 levels were significantly elevated in total SSc patients compared to normal controls ( $\mathrm{p}<0.01$; Fig. 1$)$. DM was shown as a disease control, and the serum sCD163 levels were also significantly elevated in DM patients compared to normal controls $(\mathrm{p}<0.0001$; Fig. 1 ). Concerning the SSc subgroups, there was no significant difference in serum sCD163 levels between dSSc and ISSc patients. Values higher than the mean + 3 SD (807.057 $\mathrm{ng} / \mathrm{mL}$ ) of the control serum samples were considered to be elevated in this study. Elevated sCD163 levels were observed in $32 \%$ (18/56) of total SSc patients. Regarding the subsets of SSc, serum sCD163 levels were elevated in $56 \%$ (17/32) of dSSc patients and $44 \%(10 / 24)$ of ISSc patients. By contrast, none of normal controls showed elevated sCD163 levels. Thus, serum sCD163 levels were elevated in SSc patients with similar levels between dSSc and ISSc.

Clinical correlation of sCD163 levels in SSc

SSc patients with elevated serum sCD163 levels had significantly elevated serum levels of IgG $(p<0.05)$ than those with normal sCD163 levels (Table 1). Furthermore, serum sCD163 levels correlated positively with PI ( $p=0.0009, r=0.534, n=40$; Fig. 2) in patients with SSc. Although there was no correlation between serum sCD163 levels and lung function tests including \%VC and \%DLco, SSc patients with pulmonary fibrosis (PF) had significantly elevated serum levels of sCD163 as comparison to those without $\mathrm{PF}(\mathrm{p}<0.05$, Fig. 3). Furthermore, SSc patients with elevated sCD163 levels showed higher levels of immunoglobulin (Ig)G ( $<<0.05$, Fig. 4). Thus, elevated sCD163 levels were associated with elevated serum levels of IgG. 


\section{Discussion}

Using Abs to sCD163, examinations of sCD163 levels have been reported in some diseases[19-21]. We have already reported high values of serum 8-isoprostane, that is one of the markers of lipid peroxidation, in SSc patients[8]. Although SSc is considered to be one of oxidative stresses, there have been no reports concerning sCD163 in SSc patients to our knowledge. Therefore, we conducted the present study, which was the first to reveal that serum sCD163 levels were significantly increased in SSc patients compared to healthy controls. Furthermore, we confirmed the positive correlation between serum 8-isoprostane levels and serum sCD163 levels ( $\mathrm{p}=0.0026$, $\mathrm{r}=0.460$, Data not shown). Therefore, it was strongly confirmed that oxidative stress levels were enhanced and that sCD163 was related to the level of oxidative stress in SSc patients. However, sCD163 levels did not correlate with the extent of skin sclerosis since sCD163 levels were similar between dSSc and ISSc patients.

It has been reported that serum factors including heterophilic antibodies can bind to coating and detection antibodies in some ELISA systems using a pair of antibodies and cause the falsely elevated results[22-24]. Actually, we measured serum sCD163 using a sandwich ELISA in the present study. As RF was a representative heterophilic antibody, we measured serum levels of RF (IgM and IgG) in SSc patients examined. However, no correlation was confirmed between RF (IgM) and sCD163 and between RF (IgG) and sCD163 in the present study (Table 1). Therefore, it was assumed to be less likely that increased serum levels of sCD163 in SSc patients were falsely elevated results.

We demonstrated that serum sCD163 levels were significantly elevated not only in SSc but also DM patients, as compared to normal controls. We also confirmed the positive correlations in SSc patients between serum SCD163 levels and IgG. On the other hand, SSc patients with elevated serum sCD163 levels had significantly elevated serum levels of $\operatorname{IgG}(\mathrm{p}<0.05)$ than those with normal sCD163 levels. There were some reports showing that oxidative stress could cause damage of IgG and led to the production of IgM[25]. Thus, 
it was considered that oxidative stress which was induced in SSc, could cause the damage of Ig and that the activity of Ig became less effective. Therefore, negative feedback mechanisms induced by ineffective Ig activity might stimulate production of Ig, leading to hyper- $\gamma$-globulinemia that is one of immunologic abnormalities in SSc.

The present association of elevated serum sCD163 levels with IgG suggests that oxidative injury may play a role in the immunologic abnormalities in SSc. It has been hypothesized that immune responses to autoantigens are induced by cryptic self-epitopes that are generated by modification of the self-antigens (for example, novel cleavage, altered conformation, or tertiary structure) [26]. The exposure of cryptic self-epitopes activates potentially autoreactive $\mathrm{T}$ cells that have not previously encountered the cryptic self, thereby breaking $\mathrm{T}$ cell tolerance. In this regard, reactive oxygen species have been shown to induce modification of the self-antigens, such as metal-dependent cleavage of SSc-related autoantigens[27]. Therefore, the increase of IgG may be related to the modification of IgG by oxidative injury.

We confirmed that SSc patients with PF had significantly elevated serum levels of sCD163 than those without PF in the present study. Furthermore, it was strongly confirmed that oxidative stress levels were enhanced and that sCD163 was related to the level of oxidative stress in SSc patients as mentioned before. Although there was no correlation between serum sCD163 values and lung function tests, it can be speculated that oxidative injury may contribute to lung damage, which result in pulmonary fibrosis in SSc. Exact mechanism is still unclear. Further examination should be expected in the near future.

In this study, serum sCD163 levels correlated with renal vascular damage in SSc. Vascular endothelial dysfunction is one of the central events in SSc, and cold- and stress-induced vasospasm (Raynaud's phenomenon) is the most characteristic sign that reflects this dysfunction. Raynaud's phenomenon occurs not only in the fingers and toes but also in the internal organs, such as the kidney[28]. Ischaemia and reperfusion injury following Raynaud's 
phenomenon can generate reactive oxygen species that may result in vascular endothelial damage $[29,30]$. Therefore, the finding that serum sCD163 levels correlated with renal vascular resistance in SSc suggests that excessive oxidative stress is related to vascular damage in SSc.

In conclusion, serum sCD163 levels were increased in patients with SSc as compared to normal controls and showed a positive correlation with PI and IgG in SSc patients in the present study. These results led us to the possibility that oxidative stress may be involved in immunologic abnormalities in SSc. Therefore, more detailed and sensitive examination will become possible by adding the measure of serum sCD163 to going examinations.

\section{Acknowledgements}

This work was supported by a grant of Research on Intractable Diseases form the Ministry of Health, Labour and Welfare of Japan.

Disclosures None 
Table 1. Clinical and laboratory data of patients with SSc showing elevated serum sCD163 levels at the first evaluation.

Elevated serum sCD163 Normal serum sCD163

\begin{tabular}{|c|c|c|}
\hline & $(n=18)$ & $(n=38)$ \\
\hline Age at onset $(\mathrm{yr})$ means $\pm \mathrm{SD}$ & $50.0 \pm 16.3$ & $43.5 \pm 17.4$ \\
\hline Sex (male: female) & $1: 17$ & $5: 33$ \\
\hline Duration (yr) means \pm SD & $6.1 \pm 8.7$ & $5.3 \pm 6.8$ \\
\hline
\end{tabular}

Clinical features:

dSSc
lSSc
Pitting scars
Contracture of phalanges
Organ involvement:
Lung
$\%$ means \pm SD
$\% D L c o \quad$ means \pm SD

Oesophagus

Heart

Kidney

Joint

Muscle

RF (IgM)

Prevalence (ratio)

Titer $(\mathrm{IU} / \mathrm{ml})$ means $\pm \mathrm{SD}$

RF (IgG)

Prevalence (ratio)

Titer (Index) means \pm SD

Autoantibodies:

Anti-topoisomerase I Ab

Anti-centromere $\mathrm{Ab}$

Immunoglobulin:

$$
\operatorname{IgG}(\mathrm{ng} / \mathrm{dl}) \text { means } \pm \mathrm{SD}
$$

56

44

50

56

50

34

$87.4 \pm 30.0$

$57.4 \pm 19.7$

50

14

6

11

17

$3 / 18$

$9.8 \pm 17.9$

$1 / 18$
$1.8 \pm 0.4$

50

39

37

37

$1898.8 \pm 532.8^{*}$

$1609.2 \pm 543.4$ 


$$
\begin{array}{lll}
\operatorname{IgA}(\mathrm{ng} / \mathrm{dl}) \text { means } \pm \mathrm{SD} & 353.9 \pm 180.2 & 317.0 \pm 136.9 \\
\operatorname{IgM}(\mathrm{ng} / \mathrm{dl}) \text { means } \pm \text { SD } & 235.9 \pm 174.9 & 175.6 \pm 80.0
\end{array}
$$

Values of clinical features and organ involvement are percentages unless otherwise indicated. All the clinical and laboratory parameters and serum CD163 levels were obtained at the first evaluation. $\quad * \mathrm{P}<0.05$ or $* * \mathrm{P}<0.01$ vs SSc patients with normal CD163 level 


\section{Legends}

Table 1. Clinical and laboratory data of patients with SSc showing elevated serum sCD163 levels at the first evaluation. Values of clinical features and organ involvement are percentages.

Fig. 1. Serum levels of sCD163 in patients with dSSc or ISSc and DM as compared to normal controls at the first evaluation. Serum sCD163 levels were determined by a specific ELISA. In the box and whisker plots, the $25^{\text {th }}$ to $75^{\text {th }}$ percentiles are represented by the horizontal lines of the box; the median is indicated by the internal horizontal line across the box, and the whiskers on each box represent the $10^{\text {th }}$ to $90^{\text {th }}$ percentiles. The numbers of subjects examined and mean values \pm SD are indicated in parentheses. A broken line indicates the cut-off value (mean + 3SD of the control samples).

Fig. 2. The positive correlation of serum sCD163 levels against PI in patients with SSc at the first evaluation. Serum levels of sCD163 were determined by a specific ELISA. The PI is a parameter for renal vascular resistance determined by color-flow Doppler ultrasonography of the renal interlobular arteries of both kidneys.

Fig. 3. Serum levels of sCD163 in SSc patients with or without pulmonary fibrosis at the first evaluation. In the box and whisker plots, the $25^{\text {th }}$ to $75^{\text {th }}$ percentiles are represented by the horizontal lines of the box; the median is indicated by the internal horizontal line across the box, and the whiskers on each box represent the $10^{\text {th }}$ to $90^{\text {th }}$ percentiles. The numbers of subjects examined and mean values \pm SD were indicated in parentheses..

Fig. 4 Serum levels of IgG in patients with SSc showing elevated and normal serum sCD163 levels at the first evaluation. In the box and whisker plots, the $25^{\text {th }}$ to $75^{\text {th }}$ percentiles are represented by the horizontal lines of the box; the median is indicated by the internal horizontal line across the box, and the whiskers on each box represent the $10^{\text {th }}$ to $90^{\text {th }}$ percentiles. The numbers of subjects examined and mean values \pm SD are indicated in parentheses. 


\section{References}

1. Douvas, A.S., Achten, M., Tan, E.M. (1979) Identification of a nuclear protein (Scl-70) as a unique target of human antinuclear antibodies in scleroderma. $J$ Biol Chem 254, 10514-22.

2. Moroi, Y., Peebles, C., Fritzler, M.J., Steigerwald, J., Tan, E.M. (1980) Autoantibody to centromere (kinetochore) in scleroderma sera. Proc Natl Acad Sci U S A 77, 1627-31.

3. Kuwana, M., Kaburaki, J., Mimori, T., Tojo, T., Homma, M. (1993) Autoantibody reactive with three classes of RNA polymerases in sera from patients with systemic sclerosis. J Clin Invest 91, 1399-404.

4. Herrick, A.L., Rieley, F., Schofield, D., Hollis, S., Braganza, J.M., Jayson, M.I. (1994) Micronutrient antioxidant status in patients with primary Raynaud's phenomenon and systemic sclerosis. J Rheumatol 21, 1477-83.

5. Sambo, P., Baroni, S.S., Luchetti, M., Paroncini, P., Dusi, S., Orlandini, G., Gabrielli, A. (2001) Oxidative stress in scleroderma: maintenance of scleroderma fibroblast phenotype by the constitutive up-regulation of reactive oxygen species generation through the NADPH oxidase complex pathway. Arthritis Rheum 44, 2653-64.

6. Emerit, I., Filipe, P., Meunier, P., Auclair, C., Freitas, J., Deroussent, A., Gouyette, A., Fernandes, A. (1997) Clastogenic activity in the plasma of scleroderma patients: a biomarker of oxidative stress. Dermatology 194, 140-6.

7. Murrell, D.F. (1993) A radical proposal for the pathogenesis of scleroderma. $J$ Am Acad Dermatol 28, 78-85.

8. Ogawa, F., Shimizu, K., Muroi, E., Hara, T., Hasegawa, M., Takehara, K., Sato, S. (2006) Serum levels of 8-isoprostane, a marker of oxidative stress, are 
elevated in patients with systemic sclerosis. Rheumatology (Oxford) 45, 815-8.

9. Law, S.K., Micklem, K.J., Shaw, J.M., Zhang, X.P., Dong, Y., Willis, A.C., Mason, D.Y. (1993) A new macrophage differentiation antigen which is a member of the scavenger receptor superfamily. Eur J Immunol 23, 2320-5.

10. Sulahian, T.H., Hogger, P., Wahner, A.E., Wardwell, K., Goulding, N.J., Sorg, C., Droste, A., Stehling, M., Wallace, P.K., Morganelli, P.M., Guyre, P.M. (2000) Human monocytes express CD163, which is upregulated by IL-10 and identical to p155. Cytokine 12, 1312-21.

11. Madsen, M., Moller, H.J., Nielsen, M.J., Jacobsen, C., Graversen, J.H., van den Berg, T., Moestrup, S.K. (2004) Molecular characterization of the haptoglobin.hemoglobin receptor CD163. Ligand binding properties of the scavenger receptor cysteine-rich domain region. J Biol Chem 279, 51561-7.

12. Levy, A.P., Purushothaman, K.R., Levy, N.S., Purushothaman, M., Strauss, M., Asleh, R., Marsh, S., Cohen, O., Moestrup, S.K., Moller, H.J., Zias, E.A., Benhayon, D., Fuster, V., Moreno, P.R. (2007) Downregulation of the hemoglobin scavenger receptor in individuals with diabetes and the Hp 2-2 genotype: implications for the response to intraplaque hemorrhage and plaque vulnerability. Circ Res 101, 106-10.

13. LeRoy, E.C., Black, C., Fleischmajer, R., Jablonska, S., Krieg, T., Medsger, T.A., Jr., Rowell, N., Wollheim, F. (1988) Scleroderma (systemic sclerosis): classification, subsets and pathogenesis. J Rheumatol 15, 202-5.

14. Bohan, A., Peter, J.B. (1975) Polymyositis and dermatomyositis (first of two parts). $N$ Engl J Med 292, 344-7.

15. Steen, V.D., Powell, D.L., Medsger, T.A., Jr. (1988) Clinical correlations and prognosis based on serum autoantibodies in patients with systemic sclerosis. Arthritis Rheum 31, 196-203.

16. Sato, S., Ihn, H., Kikuchi, K., Takehara, K. (1994) Antihistone antibodies in systemic sclerosis. Association with pulmonary fibrosis. Arthritis Rheum 37, 
391-4.

17. Shimizu, K., Ogawa, F., Muroi, E., Hara, T., Komura, K., Bae, S.J., Sato, S. (2007) Increased serum levels of nitrotyrosine, a marker for peroxynitrite production, in systemic sclerosis. Clin Exp Rheumatol 25, 281-6.

18. Nishijima, C., Sato, S., Hasegawa, M., Nagaoka, T., Hirata, A., Komatsu, K., Takehara, K. (2001) Renal vascular damage in Japanese patients with systemic sclerosis. Rheumatology (Oxford) 40, 406-9.

19. Fabriek, B.O., Moller, H.J., Vloet, R.P., van Winsen, L.M., Hanemaaijer, R., Teunissen, C.E., Uitdehaag, B.M., van den Berg, T.K., Dijkstra, C.D. (2007) Proteolytic shedding of the macrophage scavenger receptor CD163 in multiple sclerosis. J Neuroimmunol 187, 179-86.

20. Moller, H.J., Gronbaek, H., Schiodt, F.V., Holland-Fischer, P., Schilsky, M., Munoz, S., Hassanein, T., Lee, W.M. (2007) Soluble CD163 from activated macrophages predicts mortality in acute liver failure. J Hepatol 47, 671-6.

21. Baeten, D., Moller, H.J., Delanghe, J., Veys, E.M., Moestrup, S.K., De Keyser, F. (2004) Association of CD163+ macrophages and local production of soluble CD163 with decreased lymphocyte activation in spondylarthropathy synovitis. Arthritis Rheum 50, 1611-23.

22. Todd, D.J., Knowlton, N., Amato, M., Frank, M.B., Schur, P.H., Izmailova, E.S., Roubenoff, R., Shadick, N.A., Weinblatt, M.E., Centola, M., Lee, D.M. Erroneous augmentation of multiplex assay measurements in patients with rheumatoid arthritis due to heterophilic binding by serum rheumatoid factor. Arthritis Rheum 63, 894-903.

23. Hoofnagle, A.N., Wener, M.H. (2009) The fundamental flaws of immunoassays and potential solutions using tandem mass spectrometry. J Immunol Methods 347, 3-11.

24. Zhuang, H., Narain, S., Sobel, E., Lee, P.Y., Nacionales, D.C., Kelly, K.M., Richards, H.B., Segal, M., Stewart, C., Satoh, M., Reeves, W.H. (2005) 
Association of anti-nucleoprotein autoantibodies with upregulation of Type I interferon-inducible gene transcripts and dendritic cell maturation in systemic lupus erythematosus. Clin Immunol 117, 238-50.

25. Ligier, S., Fortin, P.R., Newkirk, M.M. (1998) A new antibody in rheumatoid arthritis targeting glycated IgG: IgM anti-IgG-AGE. $\mathrm{Br} J$ Rheumatol 37, 1307-14.

26. Casciola-Rosen, L., Rosen, A. (1997) Ultraviolet light-induced keratinocyte apoptosis: a potential mechanism for the induction of skin lesions and autoantibody production in LE. Lupus 6, 175-80.

27. Casciola-Rosen, L., Wigley, F., Rosen, A. (1997) Scleroderma autoantigens are uniquely fragmented by metal-catalyzed oxidation reactions: implications for pathogenesis. J Exp Med 185, 71-9.

28. Cannon, P.J., Hassar, M., Case, D.B., Casarella, W.J., Sommers, S.C., LeRoy, E.C. (1974) The relationship of hypertension and renal failure in scleroderma (progressive systemic sclerosis) to structural and functional abnormalities of the renal cortical circulation. Medicine (Baltimore) 53, 1-46.

29. Butler, A.R., Flitney, F.W., Williams, D.L. (1995) NO, nitrosonium ions, nitroxide ions, nitrosothiols and iron-nitrosyls in biology: a chemist's perspective. Trends Pharmacol Sci 16, 18-22.

30. Suematsu, M., Wakabayashi, Y., Ishimura, Y. (1996) Gaseous monoxides: a new class of microvascular regulator in the liver. Cardiovasc Res 32, 679-86. 


\section{Fig 1}

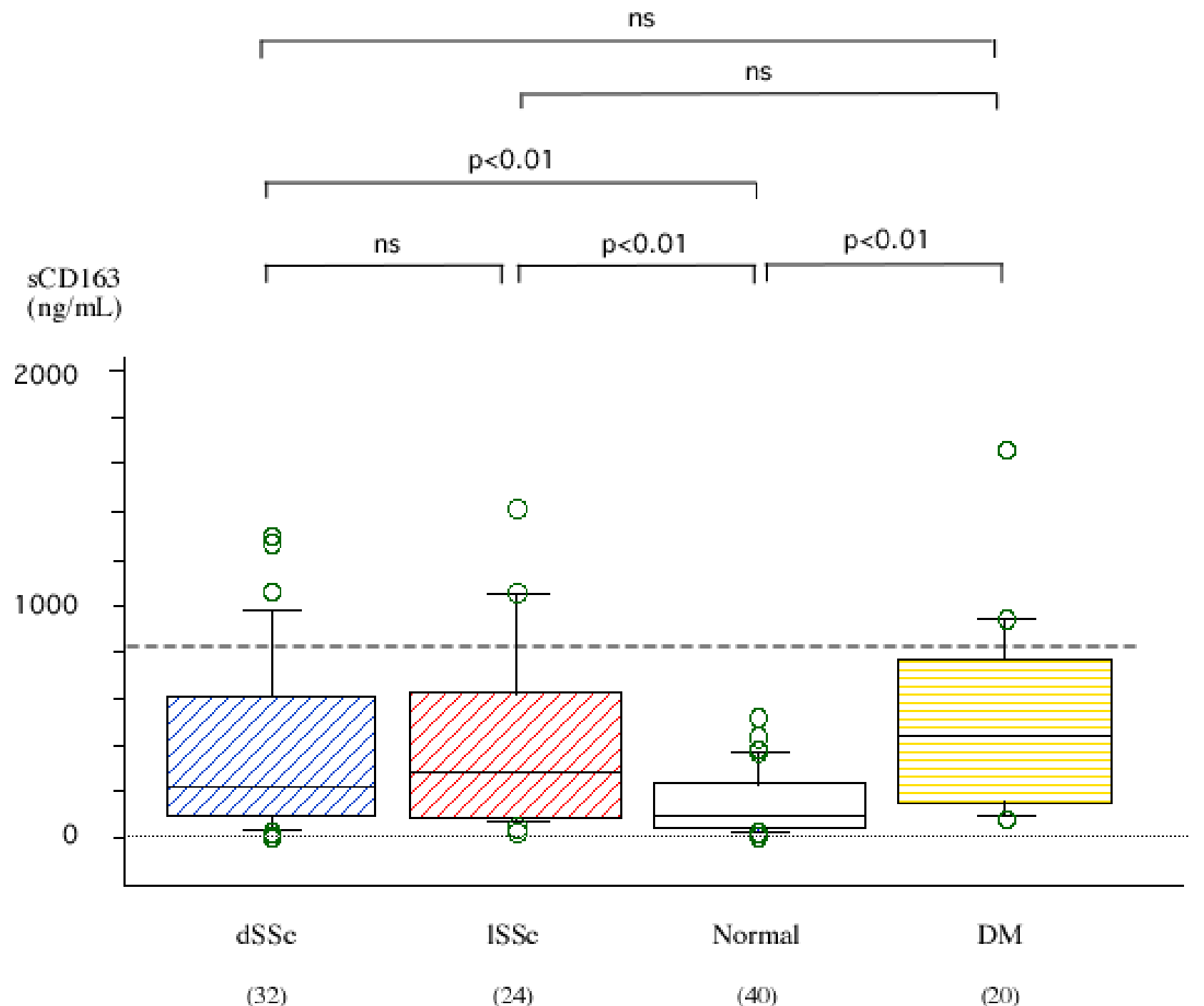

$(362.8 \pm 362.1)$

$(416.7 \pm 390.3)$

(186.4士 206.9)

$(499.2 \pm 399.7)$ 


\section{Fig 2}

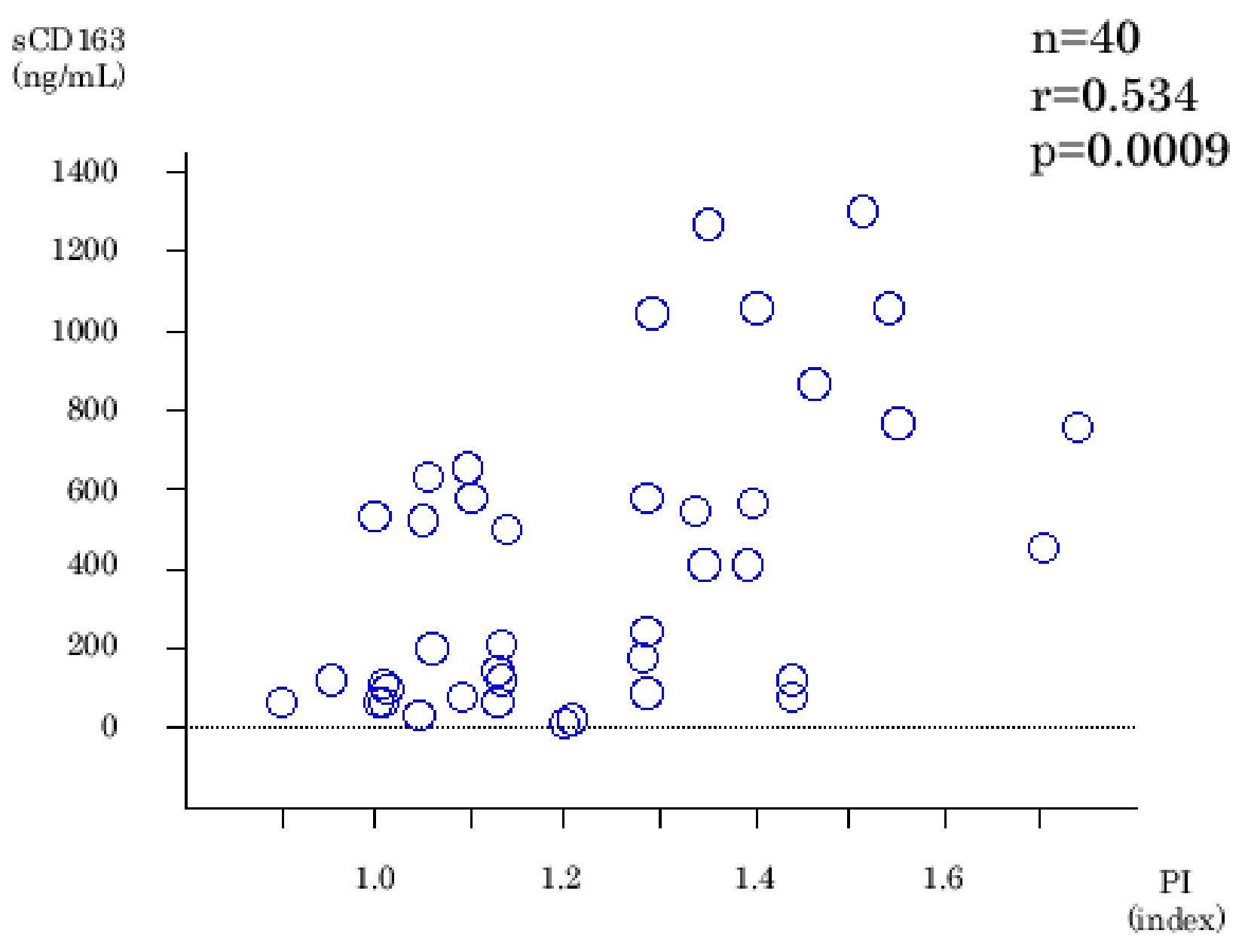




\section{Fig 3}

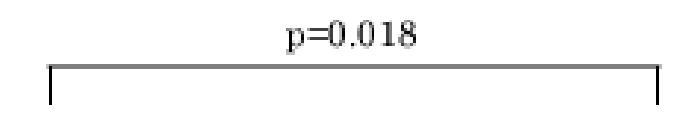

\section{sCD 163}

(ng/mL)

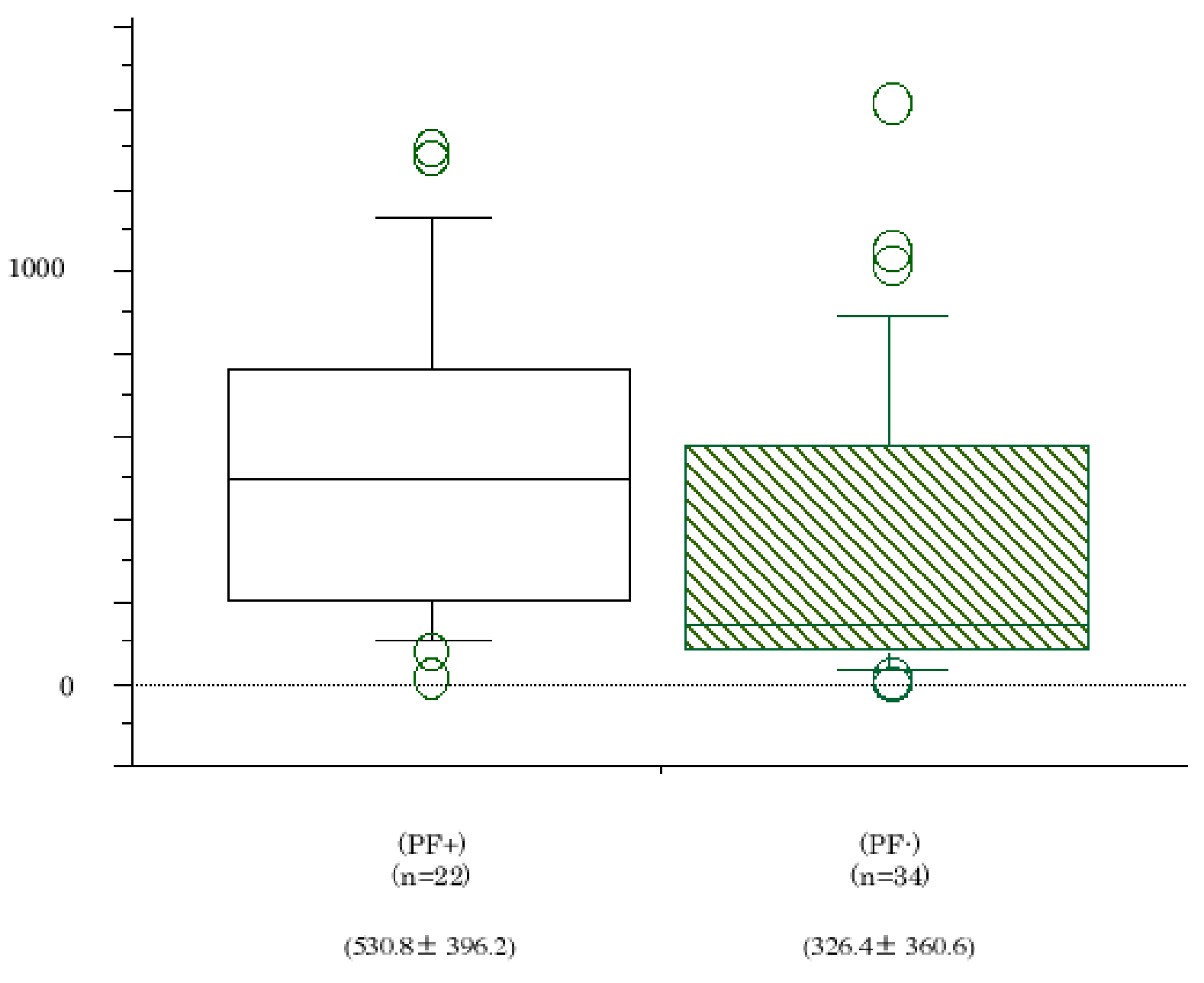


Fig 4

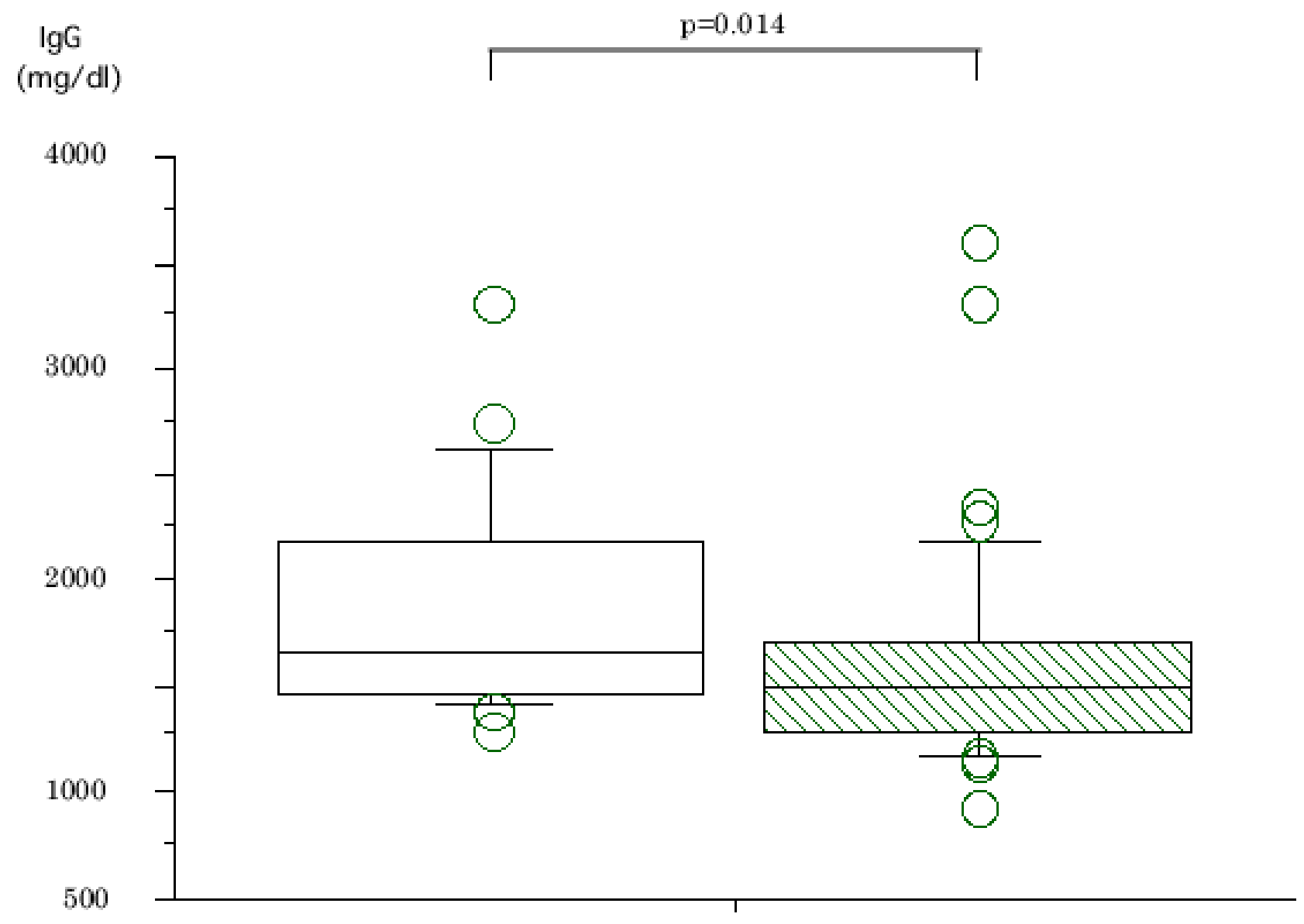

Elevated

$(\mathrm{n}=18)$

$(1898.8 \pm 532.8)$
Normal

$(\mathrm{n}=38)$

$(1609.2 \pm 543.4)$ 